\title{
Improving outcomes in patients with melanoma: strategies to ensure an early diagnosis
}

This article was published in the following Dove Press journal:

Patient Related Outcome Measures

6 November 2015

Number of times this article has been viewed

\author{
Rachel K Voss' \\ Tessa N Woods' \\ Kate D Cromwell' \\ Kelly C Nelson ${ }^{2}$ \\ Janice N Cormier' \\ 'Department of Surgical Oncology, \\ ${ }^{2}$ Department of Dermatology, The \\ University of Texas MD Anderson \\ Cancer Center, Houston, TX, USA
}

Correspondence: Janice N Cormier Department of Surgical Oncology, Unit 1484, The University of Texas MD Anderson Cancer Center, I 400 Pressler Street, PO Box 301402, Houston,

TX 77030-1402, USA

Tel + I 7137926949

Fax + I 7137451921

Email jcormier@mdanderson.org
Abstract: Patients with thin, low-risk melanomas have an excellent long-term prognosis and higher quality of life than those who are diagnosed at later stages. From an economic standpoint, treatment of early stage melanoma consumes a fraction of the health care resources needed to treat advanced disease. Consequently, early diagnosis of melanoma is in the best interest of patients, payers, and health care systems. This review describes strategies to ensure that patients receive an early diagnosis through interventions ranging from better utilization of primary care clinics, to in vivo diagnostic technologies, to new "apps" available in the market. Strategies for screening those at high risk due to age, male sex, skin type, nevi, genetic mutations, or family history are discussed. Despite progress in identifying those at high risk for melanoma, there remains a lack of general consensus worldwide for best screening practices. Strategies to ensure early diagnosis of recurrent disease in those with a prior melanoma diagnosis are also reviewed. Variations in recurrence surveillance practices by type of provider and country are featured, with evidence demonstrating that various imaging studies, including ultrasound, computed tomography, positron emission tomography, and magnetic resonance imaging, provide only minimal gains in life expectancy, even for those with more advanced (stage III) disease. Because the majority of melanomas are attributable to ultraviolet radiation in the form of sunlight, primary prevention strategies, including sunscreen use and behavioral interventions, are reviewed. Recent international government regulation of tanning beds is described, as well as issues surrounding the continued use artificial ultraviolet sources among youth. Health care stakeholder strategies to minimize UV exposure are summarized. The recommendations encompass both specific behaviors and broad intervention targets (eg, individuals, social spheres, organizations, celebrities, governments).

Keywords: melanoma, screening, early diagnosis, high-risk melanoma, recurrence, prevention

\section{Introduction}

In 2015, an estimated 73,870 US citizens will learn they have invasive melanoma, and an additional 63,440 people will receive a diagnosis of melanoma in situ. ${ }^{1}$ Early detection remains the most important predictor of melanoma survival. If treatment outcomes and overall survival (OS) are to improve, current practices must be evaluated to ensure effective diagnosis and treatment.

For more than 150 years, surgical excision of early melanoma has proven curative for many patients. This widely accepted fact likely was first detailed in 1840 by Dr Samuel Cooper, a British surgeon, in his book The First Lines of the Theory and Practice of Surgery. ${ }^{2}$ Pathologic disease stage, dictated by primary tumor characteristics like Breslow thickness and ulceration and regional nodal and metastatic disease status, has repeatedly been shown to predict outcome..$^{3-5}$ Considering the excellent outcomes 
experienced by patients with thin, low-risk melanomas, education, awareness, and skin screening represent the earliest opportunities for diagnosis.

For patients with melanoma in situ (stage 0 ) and a lowrisk subset of stage IA melanoma $(\leq 0.75 \mathrm{~mm}$ Breslow thickness, without ulceration or mitotic figures), the treatment is wide local excision alone. For patients with higher risk primary tumors $(>0.75-1 \mathrm{~mm}$ Breslow thickness), sentinel lymph node biopsy provides pathologic staging of regional lymph node basins. Complete lymph node dissection, adjuvant systemic therapy, and radiation are considered for those with more advanced stages of disease. ${ }^{6}$ Lymph node dissections are not infrequently associated with complications including infection, wound separation, seroma, and chronic lymphedema. ${ }^{7-9}$ Likewise, systemic therapy, which may include chemotherapy, BRAF inhibitors, and/or immunotherapy, introduces potential toxicity. ${ }^{6,10-14}$

\section{Quality-of-life considerations}

Early diagnosis is associated with improved quality of life for patients with melanoma. A Belgian study of 395 melanoma patients evaluated with the EQ-5D-5L questionnaire reported that postoperative stage I-II patients experienced better health-related quality of life $>2$ years after treatment than postoperative patients with stage III melanoma at least 4 months after treatment. ${ }^{15}$ Similarly, in a German study of 664 melanoma patients evaluated with the EORTC-QLQ-C30 questionnaire at least 2 years following cancer treatment, patients with regional nodal disease had worse global quality of life (odds ratio [OR] 3.34, 95\% confidence interval [CI] 1.4-8.0) than patients with no nodal disease. ${ }^{16}$ Because those with stage III disease generally undergo therapeutic lymph node dissection and possible adjuvant pharmacologic therapy, the stage-appropriate treatments likely contribute to worsened quality of life. Adjuvant low-dose interferon-alpha (IFN- $\alpha$ ) treatment has been associated with clinically meaningful, significantly worse scores for health-related quality of life in patients with stage II and III disease compared to those who did not receive (IFN- $\alpha$ ) treatment. ${ }^{13,14}$

\section{Cost savings from early diagnosis}

Although cost generally is a secondary consideration in cancer treatment, early diagnosis may provide cost savings. The estimated US direct medical cost for prevalent melanoma in 2004 was $\$ 291$ million (US dollars). ${ }^{17}$ When indirect medical costs such as patient time, lost wages, and lost future earning potential attributable to early death are also taken into consideration, the estimated annual cost ballooned to
\$3.1 billion US dollars in $2004 .{ }^{17}$ Morris et al conducted a study of annual melanoma costs in the United Kingdom. Direct medical costs were estimated at $£ 24$ million in 2002 UK pounds (or \$36 million in 2002 US dollars), and direct plus indirect costs totaled $£ 138$ million 2002 UK pounds ( $\$ 207$ million in 2002 US dollars). ${ }^{18}$ These numbers are consistent with the USA's roughly doubled health expenditure per capita versus UK expenses during the early 2000s. ${ }^{19}$ Despite the spending inequalities resulting from differences in health care delivery systems, few would dispute the significance of total melanoma costs to patients, families, and the health care systems.

Numerous studies demonstrate that increased melanoma treatment costs correspond to the disease stage..$^{20-26}$ Alexandrescu calculated total health care costs by stage for up to 5 years following diagnosis of melanoma; costs increased from $\$ 4,6482008$ US dollars for in situ disease up to $\$ 159,808$ 2008 US dollars for stage IV disease. ${ }^{20} \mathrm{He}$ concluded that costs significantly decreased with early stage diagnosis. In another study, among patients with stage III melanoma who received high-dose IFN- $\alpha$ therapy versus patients with stage III disease who were observed postoperatively, the estimated cost for highdose interferon treatment per quality-adjusted life year was $\$ 85,779$ in 2005 US dollars. ${ }^{27}$ Therefore, exponential savings can likely be realized if melanoma is diagnosed early.

The cost effectiveness of melanoma screening depends greatly upon the population being screened and the method used. Losina et al used a Markov model to predict the costeffectiveness ratios per quality-adjusted life year (QALY) for visual melanoma screening in different populations. ${ }^{28}$ Annual screening in the general population over 50 was not deemed cost effective ( $\$ 586,800 /$ QALY in 2004 US dollars), but screening higher risk populations was cost effective, such as screening siblings of melanoma patients every 2 years $(\$ 35,500 / \mathrm{QALY})$ or a one-time screening in those over 50 years of age $(\$ 10,100 / \mathrm{QALY})$. A recent systematic review of the topic also concluded that early detection of melanoma targeting high-risk populations may be cost effective, but updated studies are necessary. ${ }^{29}$

\section{Initial diagnosis of melanoma}

Secondary prevention, ie, diagnosing disease as early as possible to limit morbidity and mortality, is critical for improved outcomes, quality, and cost. Johnson et al ${ }^{30}$ proposed three secondary prevention strategies that may be utilized by primary care physicians (PCPs). First, they may provide verbal guidance and written pamphlets on skin cancer identification and self-skin examination; second, PCPs may identify patients at highest risk based on family history, personal phenotype, or 
high-risk behaviors and refer to a dermatologist for screening; the third and most time-intensive strategy recommended by these authors is to train PCPs to conduct thorough skin examinations for all patients during routine office visits. The authors examined medical training, physician workload, and career expectation gaps and identified that these strategies are viable but necessitate further study before wide-scale implementation. The shortage of general practitioners in the USA is expected to worsen as the population ages $;{ }^{31}$ consequently, it is critical to identify cost-effective strategies to facilitate skin exams and early melanoma diagnosis.

Dermatologists may utilize more directed technologies to enhance early detection and minimize unnecessary diagnostic excisions. An in-depth review of these technologies is beyond the scope of this article, but in brief includes dermoscopy, reflectance confocal microscopy (an imaging technology that renders real-time images with near histologic-level resolution), automated dermoscopic analysis (MelaFind is one such technology that is FDA approved), and tape-stripping RNA analysis. Total body photography may also be utilized to obtain a baseline set of clinical images to which subsequent clinical examinations may be compared. Although some nonmalignant nevi may demonstrate interval change, nonchanging lesions are almost certainly benign and do not need to be removed. Comparison may also facilitate detection of subtle, early stage melanomas.

Outside of clinic-based primary prevention of melanoma, other resources may facilitate care and prevention for patients lacking intensive screening program access or awareness of their risk profile. ${ }^{32,33} \mathrm{~A}$ review of smartphone applications dedicated to evaluating melanoma revealed that 39 health applications (apps) were available as of July $2014 .{ }^{34}$ Of these, 22 provide patient education on clinical features of melanoma, sun-protective practices, and outline appropriate techniques for self-skin examination. Nineteen apps allowed users to upload pictures of nevi and follow them over time. Nine of the apps allowed users to ask an "expert" to review an image, usually at additional cost. The authors did not contend that these apps were validated for widespread use, and many required additional evaluations before being widely marketable. Despite these limitations, the new technology has the potential to empower patients to identify melanoma at a time when it is more easily treated.

\section{Screening and diagnosis for high-risk populations}

Melanoma is associated with a well-defined set of risk factors, which include advancing age, male sex, lighter skin pigmentation, a history of intermittent intense sunlight exposure, a history of indoor tanning bed exposure, a personal history of dysplastic nevi or prior melanoma, or a strong family history of melanoma. ${ }^{35}$ Identification of high-risk melanoma patients facilitates improved outcomes when education and surveillance guidelines are appropriately tailored.

\section{Age and sex}

Age has long been a known risk factor for melanoma, with studies reporting an increase in melanoma risk of 3.1\% per year, and investigators have postulated that DNA damage accumulates over time. ${ }^{36}$ There is no direct correlation between age, metastasis, and mortality, however. Balch et $\mathrm{al}^{37}$ reported that in a series of 7,756 melanoma subjects from the American Joint Committee on Cancer database, younger patients demonstrated a higher rate of sentinel lymph node metastasis than their older counterparts, and subjects $>70$ years of age demonstrated a lower rate of regional disease but a more aggressive primary tumor, leading to a higher mortality rate. ${ }^{37}$ In a series using 2014 National Cancer Registry data, a $2.9 \%$ risk for invasive melanoma among men was identified, with a reduced risk of $1.9 \%$ for melanoma in women. ${ }^{38}$ Thus, as a group, older men are considered at higher risk as compared to other age and sex groups.

\section{Skin type and nevi}

Phenotypes with lower pigmentary density, such as red or blond hair, lightly colored skin with multiple freckles, and blue or hazel eyes, also have been associated with an increased risk of melanoma. ${ }^{39}$ Overall, nevi are not considered premalignant lesions. Melanoma may arise from any nevus (typical or dysplastic) or normal skin. While the authors advocate for surveillance of both new and changing nevi, ${ }^{40}$ specific surveillance recommendations vary by country, professional organization, and the presence of other known risk factors.

Dermoscopy, the examination of skin using skin surface microscopy, has become an important tool in the evaluation of patients at high risk with multiple nevi. A representative clinical and dermoscopic image from a stage IA melanoma demonstrates the increased detail visible with dermoscopic examination (Figure 1). A randomized trial by Carli et al reported a reduction in the number of patients referred for biopsy ( $9 \%$ vs 15\%) and a decrease in the benign-to-malignant excision ratio from 18:1 to 4:1 following the introduction of dermoscopy into clinical practice. ${ }^{41}$ Watts et al reported in a systematic review published in 2015 that dermoscopy was particularly useful for patients with dysplastic nevi. ${ }^{42}$ 

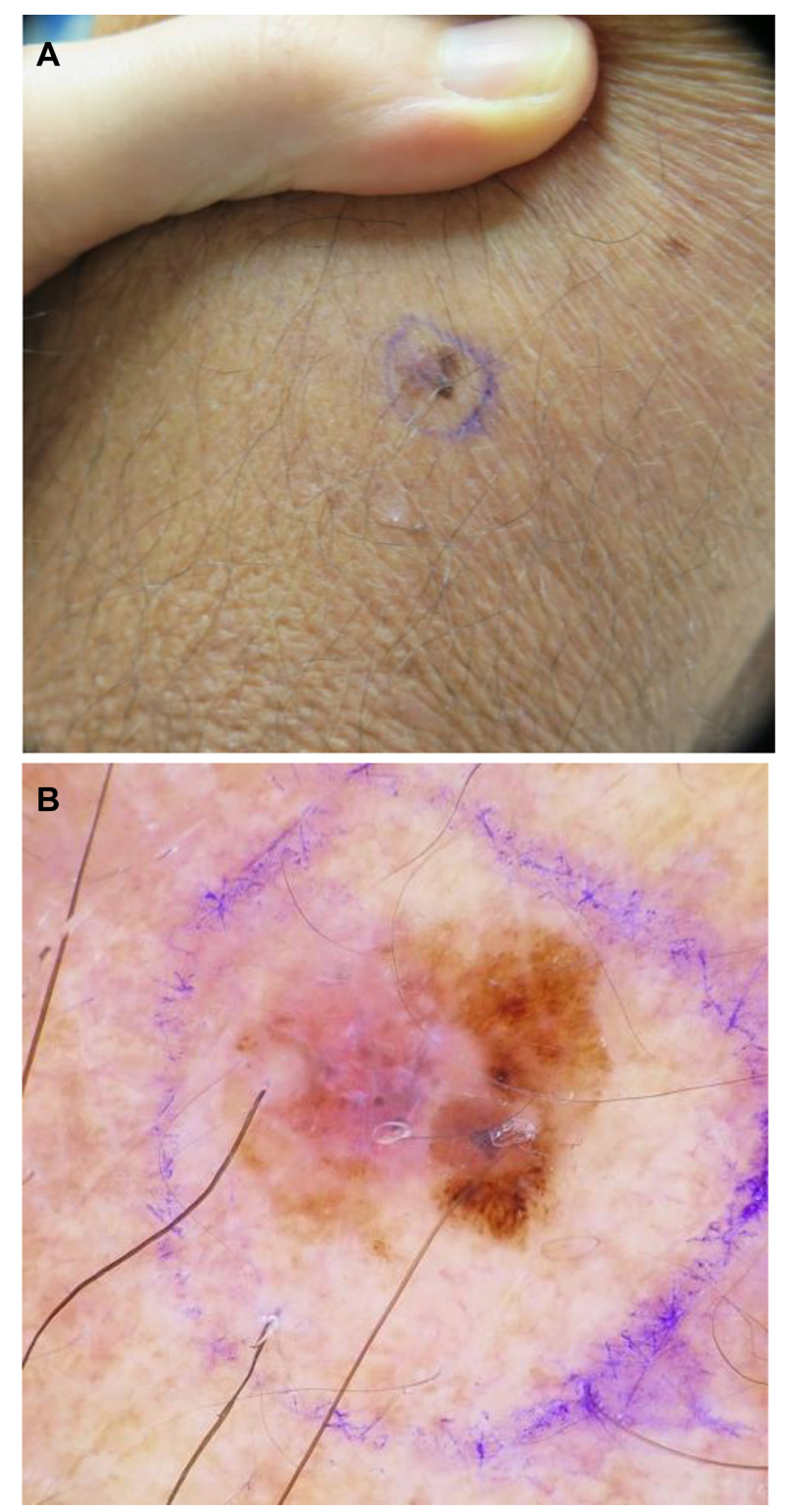

Figure I (A) Clinical image of a pink and brown macule of the left upper arm, diagnosed as a stage IA superficial spreading melanoma, with Breslow depth of $0.28 \mathrm{~mm}$. (B) Dermoscopy demonstrates a globally asymmetrical lesion, with a disorganized reticular network on the right and a milky/pink homogenous area on the left.

Widespread adoption of dermoscopy in the USA has been hampered by the need for dedicated provider training and, potentially, by the absence of provider reimbursement.

\section{Family history and genetic predisposition}

After a patient receives an initial melanoma diagnosis, his or her personal risk for a second primary melanoma is 3-8 times higher than that of the unaffected population. ${ }^{35}$ A recent meta-analysis identified eight genomic loci specifically associated with varying levels of statistically significant $(P<0.05)$ increases in melanoma risk: $M C 1 R, T Y R, T Y R P 1$, SLC45A2, ASIP/PIGU/MYH7B, and CDKN2A/MTAP ${ }^{43}$ The investigators noted there may be two different genetic drivers for melanoma development: those involved in pigmentation change and those involved in nevi development. ${ }^{43}$ Numerous studies continue to shed light on the genetic components of melanoma and define them as potential targets for treatment. Screening for patients who are genetically predisposed to melanoma may include frequent clinical exams, referral to a specialist, dermoscopy by a trained professional, total-body photography, and/or sequential digital imaging over time (Table 1). Genetic testing is generally recommended only for those with a strong family history, although the level of evidence for this recommendation is weak. ${ }^{42}$

Familial atypical multiple mole melanoma syndrome, another high-risk variant, is associated with multiple atypical dysplastic nevi (often exceeding 50) and is an autosomal-dominant disorder associated with a defect in the CDKN2A gene. ${ }^{44}$ Certain dermatology guidelines recommend digital dermoscopy every 3 months for patients with this syndrome. ${ }^{45}$

\section{Comparison of guidelines}

Despite the many ongoing studies on self-examination, physical exam, dermoscopy, and new photographic techniques, there is a lack of evidence-based guidelines and no real consensus regarding surveillance practices for high-risk patients prior to melanoma diagnosis. The most recent National Comprehensive Cancer Network guidelines contained no specific recommendations for screening high-risk populations for primary cutaneous melanoma, ${ }^{6}$ and the American Academy of Dermatology in 2010 recommended that clinicians evaluate patients at least annually and perhaps as often as every 3 months. ${ }^{46}$ A 2015 systematic review summarized 34 sets of surveillance guidelines from 20 countries and reported large variation in recommendations for surveillance technologies and exam intervals, ranging from 3 months to 12 months for patients at high risk, as summarized in Table 1.42,47-52

In 2014, Watts et $\mathrm{a}^{53}$ completed a cost analysis of dermatological surveillance for individuals deemed high risk for melanoma who received a full skin examination enhanced by dermoscopy every 6 months. If a lesion was deemed concerning for malignancy, it was excised, and the patient returned after 3 months for additional screening. A total of 102 patients were screened in this manner, with a mean annual cost per patient to the health system of \$882 in 2013 Australian dollars (\$599 in 2013 US dollars). Three early stage melanomas and eight non-melanoma skin cancers were diagnosed at a sufficiently early stage to warrant therapeutic excision with local anesthetic. The authors note that although the sample size was small, the study supported the cost 
Table I Summary of recommended screening practices that may be considered for specific high-risk populations

\begin{tabular}{|c|c|}
\hline High-risk population subsets & Additional screening practices to consider based on published guidelines \\
\hline \multirow[t]{4}{*}{ All "high-risk" patients } & Offer a surveillance program (as least annually) \\
\hline & Referral to specialist \\
\hline & Dermoscopy by trained professional \\
\hline & Total-body photography \\
\hline $\begin{array}{l}\text { Advanced age, male sex, fair skin/hair, inability to tan, prior } \\
\text { significant UV exposure }\end{array}$ & No additional recommendations \\
\hline Patient anxiety or Inability to recognize disease & Frequent clinical exams \\
\hline \multirow[t]{2}{*}{ Personal history of melanoma } & Frequent, lifetime clinical exams \\
\hline & Referral to specialist \\
\hline \multirow[t]{6}{*}{ Family history (some specify $\geq 3$ family members or melanomas) } & Frequent, lifetime clinical exams (every 3-12 months) \\
\hline & Confirm age at diagnosis and tumor pathology \\
\hline & Frequent clinical exams (start at age 12 for first-degree relatives, age 20 for \\
\hline & second-degree relatives) \\
\hline & Referral to specialist \\
\hline & Genetic testing \\
\hline \multirow[t]{8}{*}{ Multiple nevi } & Frequent, lifetime clinical exams (every 6-12 months) \\
\hline & Referral to specialist \\
\hline & Dermoscopy by trained professional \\
\hline & Total-body photography \\
\hline & Sequential digital imaging over time \\
\hline & Biopsy any changed lesions \\
\hline & Not recommended: prophylactic removal of small/medium congenital \\
\hline & or nonsuspicious lesions \\
\hline \multirow[t]{7}{*}{ Large congenital nevi $(>\mid 5-20 \mathrm{~cm})$} & Frequent, lifetime surveillance (every 6-12 months) \\
\hline & Referral to specialist \\
\hline & Total-body photography \\
\hline & Sequential digital imaging over time \\
\hline & Biopsy any changed nevi \\
\hline & Consider prophylactic removal of nevus \\
\hline & Newborns: MRI within the first 6 months of life \\
\hline \multirow[t]{8}{*}{ Dysplastic nevi } & Comprehensive personal and family history \\
\hline & Frequent, lifetime clinical exams (every 3-12 months) \\
\hline & Referral to specialist \\
\hline & Dermoscopy by trained professional \\
\hline & Total-body photography \\
\hline & Sequential digital imaging over time \\
\hline & Biopsy any changed lesions \\
\hline & Not recommended: prophylactic removal of nevi \\
\hline Genetic mutations (MCIR, TYR, TYRPI, SLC45A2, & Frequent clinical exams \\
\hline \multirow[t]{4}{*}{ ASIP/PIGU/MYH7B) } & Referral to specialist \\
\hline & Dermoscopy by trained professional \\
\hline & Total-body photography \\
\hline & Sequential digital imaging over time \\
\hline Familial atypical multiple mole melanoma syndrome & Dermoscopy every 3 months by trained professional \\
\hline \multirow[t]{2}{*}{$(C D K N 2 A / M T A P)$} & Research only: referral to gastrointestinal specialist at age 45 or if family \\
\hline & history of pancreatic cancer \\
\hline Transplant recipients or those chronically immunosuppressed & Referral to specialist \\
\hline
\end{tabular}

Abbreviations: UV, ultraviolet; MRI, magnetic resonance imaging.

effectiveness of intensive screening for those at highest risk of cutaneous malignancy. ${ }^{53}$

Controversy remains regarding the value of selfexamination. While only $23 \%-61 \%$ of the general population worldwide engages in skin self-examination ${ }^{54}$ and only $24.1 \%$ of patients at high-risk perform an optimal self-exam defined as a monthly exam covering at least $80 \%$ of the body surface, ${ }^{55}$ the National Cancer Institute conducted a population-based 
case-control study of 1,199 patients that suggested a possible decrease in mortality by as much as $63 \%$ for patients who practiced self-examination. ${ }^{56}$ Shortly thereafter, the US Preventive Services Task Force (USPSTF) stated that evidence demonstrating improved outcomes resulting from self-examination was still lacking. ${ }^{57}$ Azoury and Lange stated in Surgical Clinics of North America that "prevention and early detection programs lack a uniform approach worldwide, and targeting high-risk groups remains a challenge". ${ }^{58}$

\section{Diagnosis of melanoma recurrence}

Once a diagnosis of melanoma has been confirmed and treatment is completed, it is important to continue surveillance for both tumor recurrence and additional primary melanomas - both of which pose ongoing risk.

\section{Current practices}

In 2012, Cromwell et al $^{59}$ completed a systematic review to evaluate worldwide melanoma surveillance practices. Peerreviewed literature from three medical indices was examined, and all articles that had an English translation were reviewed. A total of 43 articles were identified that discussed melanoma surveillance practices in Australia/New Zealand, Canada, Germany, the UK, the USA, the Netherlands, and Switzerland. An evaluation of surveillance practices by country identified several different practices. Among patients treated for stage I melanoma, the frequency of skin examinations ranged from one to six visits per year during the first 5 years after diagnosis, and, in certain instances, included an ultrasound of the regional nodal basin, chest X-ray, or photography. The highest intensity screening was observed in the UK. Patients with a history of stage II disease were screened at similar frequencies worldwide; however, imaging recommendations also included a computed tomography (CT) scan of the chest, abdomen, and pelvis in Germany and in the USA. For patients with stage III melanoma, surveillance was recommended two to four times per year, often including various imaging modalities and brain imaging. The findings of this systematic review are summarized in Table 2.

In the same systematic review, ${ }^{59}$ surveillance strategies were identified and stratified by type of health care provider (eg, general practitioner, dermatologist, medical oncologist, or surgical oncologist), as shown in Table 3. Among these practices, the only universal recommendation was for patient self-examination of skin and nodal basins. General practitioners saw patients with all stages of disease four times per year but generally did not obtain surveillance imaging. Dermatologists, medical oncologists, and surgical oncologists all exercised more intensive surveillance both in terms of the number of examinations and types of imaging obtained, which increased progressively with stage.

\section{Surveillance imaging}

Imaging is a widely used tool to detect recurrence. Imaging of the regional nodal basins can be accomplished in patients with melanoma with ultrasonography, which is thought to be most sensitive, or with CT with or without positron emission tomography (PET) or magnetic resonance imaging (MRI) to evaluate for distant metastatic disease. ${ }^{60}$ Highly utilized, nonsymptom-driven imaging may only identify late recurrences that may not be amenable to localized treatment. Risks associated with frequent imaging without a clinical indication include false-positive findings, which often necessitate additional testing such as biopsies and increase patient anxiety and cost. Additionally, radiation exposure poses risk for cumulative toxicity and second primary malignancies. ${ }^{61}$

A meta-analysis conducted by Xing et al evaluated the use of ultrasound, CT, PET, and PET/CT for staging and surveillance of patients with melanoma. ${ }^{62}$ In this analysis, a literature search identified 74 unique citations that reported patient-level data for 10,528 patients undergoing imaging for the staging or surveillance of melanoma. A Bayesian bivariate binomial model was developed to estimate the sensitivity and specificity of each test. For the primary staging of regional lymph nodes, ultrasound was the most sensitive technique (60\% median score, 95\% CI 33\%-83\%), followed by PET (30\% median score, 95\% CI 12\%-55\%), PET/CT (11\% median score, 95\% CI 1\%-50\%) and CT (9\% median score, 95\% CI 12\%-55\%). For patients with melanoma who were undergoing lymph node surveillance, the study found that ultrasound was again the most sensitive technique (96\% median score, 95\% CI 85\%-99\%). PET/CT was the most sensitive modality for both staging and surveillance of distant metastases (80\% median score, 95\% CI 53\%-93\% for staging; $86 \%$ median score, 95\% CI 76\%-93\% for surveillance).

Subsequent analyses from a single institution have been completed using patient-level data from 1,600 patients treated for stages I-III melanoma between 1992 and 2007 using a probabilistic Markov model to evaluate the impact of routine surveillance for the detection of melanoma recurrence at a time at which it can be surgically treated. ${ }^{63}$ To evaluate the impact of imaging, the model assumed that $80 \%$ of regionally detected recurrences and $20 \%$ of distant recurrences identified by routine imaging could be treated surgically. Using an interval of 6 months or 12 months for surveillance strategies, 


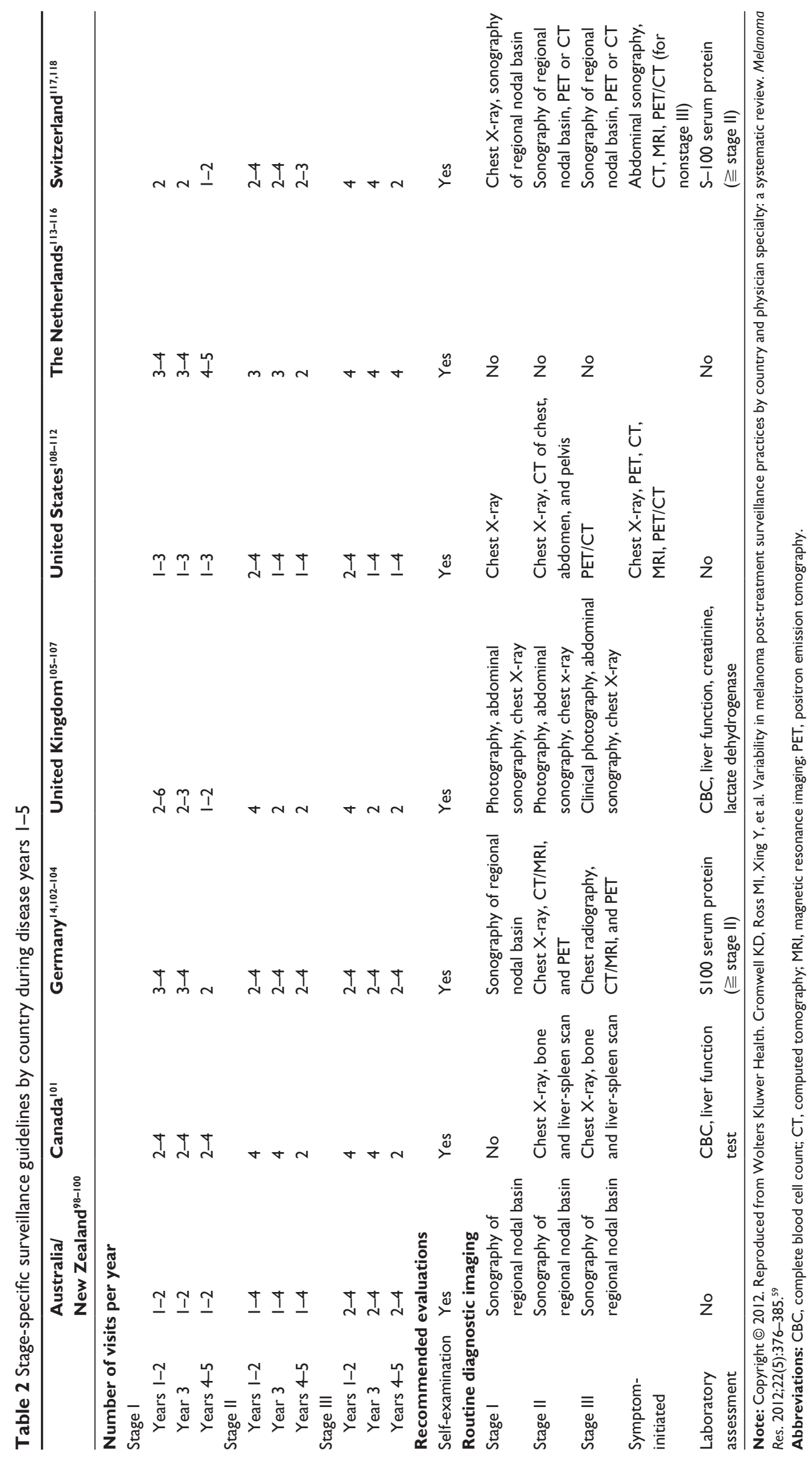


Table 3 Stage-specific surveillance guidelines by physician specialty during disease years I-5

\begin{tabular}{|c|c|c|c|c|}
\hline & General practitioner & Dermatologist & Medical oncologist & Surgical oncologist \\
\hline \multicolumn{5}{|l|}{ Number of visits per year } \\
\hline Stage I & 4 & 2 & 2 & $\mathrm{~N} / \mathrm{A}$ \\
\hline \multicolumn{5}{|l|}{ Stage II } \\
\hline Years I-2 & 4 & 4 & 4 & 4 \\
\hline Year 3 & 4 & 4 & 4 & 4 \\
\hline Years 4-5 & 4 & 4 & 4 & 2 \\
\hline \multirow[t]{2}{*}{ Stage III } & 4 & 4 & 4 & 4 (years I-3) \\
\hline & & & & 2 (years 4-5) \\
\hline \multicolumn{5}{|c|}{ Recommended evaluations } \\
\hline Self-examination & Yes & Yes & Yes & Yes \\
\hline Routine diagnostic imaging & No & CT for stage III & $\begin{array}{l}\text { Sonography of regional } \\
\text { lymph nodes }\end{array}$ & $\begin{array}{l}\text { CT of chest, abdomen, } \\
\text { and pelvis }\end{array}$ \\
\hline Laboratory assessment & No & $\mathrm{LDH}, \mathrm{AP}$, protein S-100 $\beta$ & $\mathrm{LDH}, \mathrm{AP}$ & CBC, LDH (> stage II) \\
\hline
\end{tabular}

Note: Copyright (C) 2012. Reproduced from Wolters Kluwer Health. Cromwell KD, Ross MI, Xing Y, et al. Variability in melanoma post-treatment surveillance practices by country and physician specialty: a systematic review. Melanoma Res. 2012;22(5):376-385. ${ }^{59}$

Abbreviations: AP, alkaline phosphatase; CBC, complete blood cell count; CT, computed tomography; LDH, lactate dehydrogenase; N/A, not available.

the model used CT and PET/CT to evaluate the impact of early detection on survival. For patients with stage I disease, CT imaging at 12-month intervals over 5 years detected treatable regional or distant recurrence in only $1.3 \%$ more patients than physical exam alone. ${ }^{63}$ Patients with stage IIIC disease would theoretically experience the best survival advantage with frequent surveillance imaging, but the increase in life expectancy was only 2.0 months in this subgroup when PET/ CT was obtained every 6 months. ${ }^{63}$ The study concluded that the detection of surgically treatable recurrences with imaging provides only very minimal gains in life expectancy while greatly increasing cost and resource utilization.

The survival benefit associated with early detection of melanoma recurrence was evaluated by Leiter et al. ${ }^{64}$ In this long-term survival analysis, 1,696 patients with stages I-III cutaneous melanoma were prospectively surveyed from 1996 to 1998 to evaluate the impact of lead-time bias on the diagnosis of metastatic disease. Surveillance included a combination of physical exam, ultrasound of nodal basins, abdominal ultrasound, chest X-ray, and blood draws measuring alkaline phosphatase and lactate dehydrogenase. Most tests were performed annually for patients with stages I-II disease and biannually for those with stage III disease. CT, MRI, PET scans, or other imaging techniques were used only if findings were inconclusive on the initial tests. In this cohort, 112 patients developed recurrence, and $52.7 \%$ of these recurrences were detected at an early stage. Among patients with early recurrence, $64.4 \%$ died as a result of melanoma, whereas $86 \%$ of those detected at a late stage died. Results showed a statistically significant survival benefit among patients whose metastases were detected early ( $40.5 \%$ OS) rather than late $(25.6 \% \mathrm{OS}, P=0.013)$. However, when stratified by locoregional or distant metastases, differences in OS were not statistically significant between early and late detection.

Advances in immunotherapy and targeted therapies have ushered in a new era in treating advanced and metastatic melanoma. Presently, six drugs have been approved for this use in the USA, Europe, and/or Japan (ipilimumab, nivolumab, pembrolizumab, vemurafenib, dabrafenib, and trametinib). ${ }^{65}$ Early diagnosis of recurrent or metastatic disease may lead to improved survival by optimizing early initiation of the above new therapies. Trials are going on to determine optimal timing and combination of treatments to produce maximum benefit.

\section{Primary prevention of melanoma}

Primary prevention is designed to inhibit UV radiationinduced malignant cellular transformation by increasing sun-protective behaviors and reducing indoor tanning at individual and population levels. Sun protection and indoor tanning have been recent targets by governmental regulation and behavior modification efforts.

\section{Increasing sun-protective behaviors}

The percentage of melanomas attributable to sunlight exposure ranges between $68 \%$ and $97 \% .{ }^{66}$ As a result, limiting UV radiation by changing behaviors and attitudes regarding sun exposure has the potential to eliminate the majority of malignant melanoma cases worldwide. The spectrum of concerning UV radiation includes UVA (320-400 nm) and UVB (290-320 $\mathrm{nm}$ ) rays, which induce mutagenic and immunomodulatory effects. ${ }^{67} \mathrm{UVB}$ is the main culprit behind DNA damage; however, UVA comprises $90 \%-95 \%$ of the UV spectrum that comes into contact with epithelial cells. ${ }^{67}$ Gandini et al demonstrated that intermittent sun exposure and 
sunburn history are more strongly associated with melanoma, whereas a high level of continuous exposure is protective against melanoma. ${ }^{39}$ Thus, the manner of exposure - not solely the exposure itself - is associated with increased risk.

Governments have become involved in sun exposure by endorsing sun-protective behaviors and by regulating the sale of sunscreen products. In the last 10 years, Europe, Australia, and North America have introduced tighter legislation on sunscreen and increasingly emphasized sunscreens that are "broad spectrum" (or protect against both UVA and UVB radiation) as the only sunscreens that can reduce cancer risk. ${ }^{68-71}$

Critics say insufficient evidence demonstrates that sunscreen use reduces melanoma incidence, citing poor internal validity and inconsistency in reported studies. ${ }^{72,73}$ The largest randomized adult study to test the sunscreen hypothesis was performed by Green et al as part of the Nambour Skin Cancer Prevention Trial. ${ }^{74}$ More than 1,600 patients were followed for nearly 15 years after randomization to daily application of sun protection factor (SPF) 16 sunscreen vs a comparison group that continued their usual, pretrial sunscreen application practices. While the results were of borderline statistical significance, eleven patients developed first primary melanomas (eight in situ, three invasive) in the daily sunscreen group compared to 22 patients (eleven in situ, eleven invasive) in the control group (hazard ratio [HR] 0.50, 95\% CI 0.24-1.02, $P=0.51)$.

Major skin cancer organizations, including the American Cancer Society, Cancer Council Australia, and the World Health Organization (WHO), do recommend sunscreen use to prevent skin cancer. The American Academy of Dermatology recommends everyone use broad-spectrum, waterresistant SPF 30 or higher sunscreen whenever outdoors. All areas not covered by clothing should be generously coated 15 minutes before exposure, and reapplication should occur every 2 hours and after swimming or sweating heavily; SPF 30 or higher lip balm also should be worn to protect the lips. ${ }^{75}$ Sunscreen use should be combined with other sun-protective behaviors such as limiting midday exposure, covering exposed skin with clothing, seeking shade, and monitoring the UV index. ${ }^{75-78}$

Children are particularly vulnerable to sun exposure, and children who sustain sunburns are at highest risk for developing melanoma among all age groups (OR 1.91, 95\% CI 1.59-2.30) in one meta-analysis. ${ }^{79}$ To this end, the WHO recommends teaching sun protection in schools and has developed its own curriculum, as have nations in Europe, North America, and Australia. ${ }^{80}$ The SunWise Program created by the US Environmental Protection Agency has been used in more than 40,000 schools and organizations since $2000^{81}$ and is estimated to save $\$ 2-\$ 4$ in health care and productivity losses for every dollar spent. ${ }^{82}$ Unfortunately, governmental oversight of sunscreen by the FDA has had the unintended effect of limiting sunscreen use in US schools; in many areas, a physician's note or prescription is now required to bring sunscreen to school.

Employees with occupation-related sun exposure with three or more hours of sun exposure per workday represent another group at risk for melanoma. ${ }^{83}$ The SUNWISE Letter Carriers Study, an intervention involving 70 postal stations and more than 2,000 postal workers in Southern California, randomized workers to receive educational sun safety messages and access to protective hats and sunscreen. The intervention also included visual cues as behavior prompts, placement of large pump bottles of sunscreen in locker rooms, and the distribution of sunscreen to each worker. At 2 years, those in the intervention group demonstrated significantly higher rates of sunscreen use (OR 2.0, 95\% CI 1.6-2.6) and hat use (OR 2.9, 95\% CI 2.3-3.6) versus controls. ${ }^{84}$ While workplace interventions require extra planning, time, and money to implement, they can influence individual practices, especially with a supportive workplace culture. ${ }^{83}$

Clinicians play an important role in counseling patients about sun-protective behaviors. Less than half of patients report receiving counseling about sun protection, ${ }^{85-87}$ but multiple studies have shown that when counseling is delivered, it is associated with the performance of sun-protective behaviors, especially sunscreen use. ${ }^{85,87,88}$ The USPSTF recommends counseling children, adolescents, and fair-skinned young adults younger than age 24 to limit UV radiation exposure by performing many of the behaviors listed in the left side of Table 4. However, the USPSTF concludes there is insufficient evidence of the risks versus benefits of counseling those older than 24 years of age about minimizing risk of skin cancer. ${ }^{89}$

The right side of Table 4 summarizes targets for dissemination of skin safety information. Depending on the age and demographics of the target group (young, old, male, female, urban, rural, etc) tailored messages can be created and directed at multiple target levels for maximal effect on behavior. For example, occupationally-exposed adults may be reached by influencing the workplace (target organizations), influencing individual workers' practices (target the Individual), and influencing governmental regulations regarding workplace sun exposure (partner with government and nonprofit organizations). Or, if trying to change adolescent behaviors, leveraging parents and peers (target the individual's social sphere), celebrity influence (employ mass media, celebrities, and public figures), and 
Table 4 Health care stakeholder recommendations and strategies to reduce UV radiation exposure

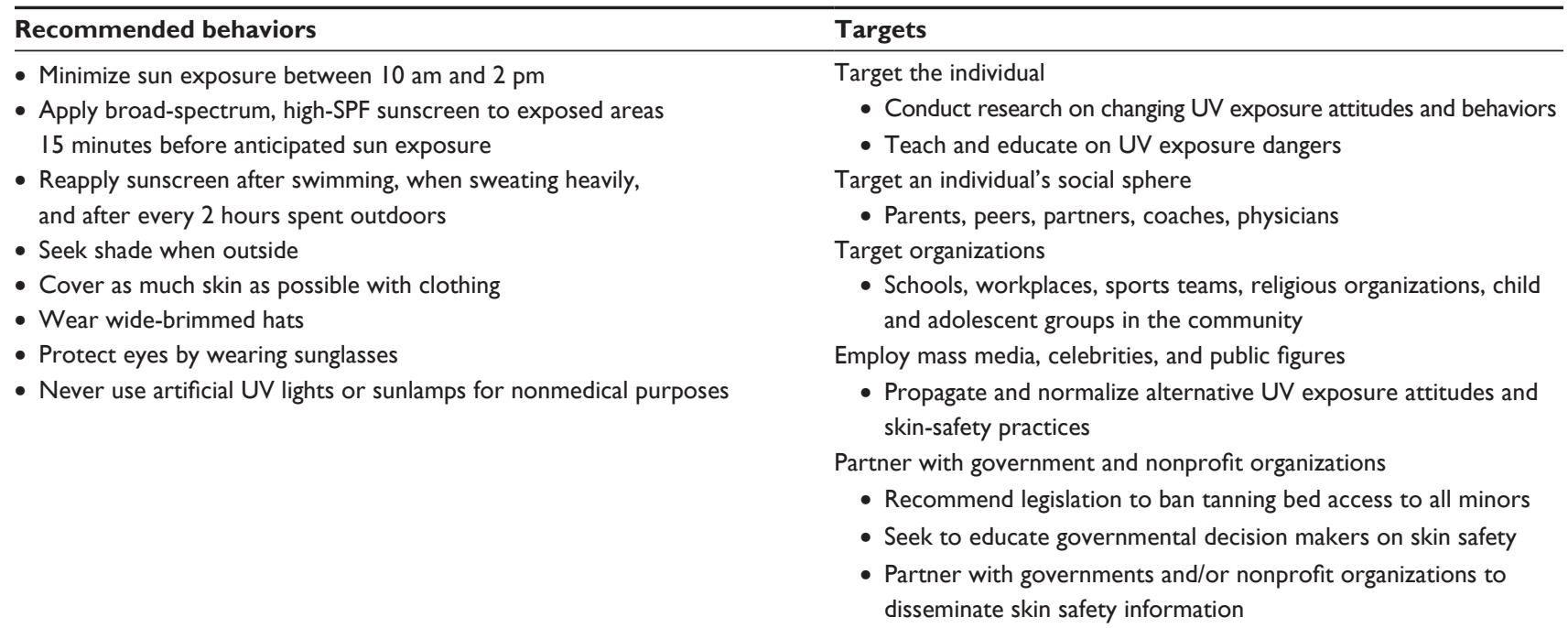

Note: Data from Holman et $\mathrm{al}^{97}$ and Mancebo et al. ${ }^{119}$

Abbreviations: SPF, sun protection factor; UV, ultraviolet.

government regulations may be the solution. The goal with all dissemination strategies is to create campaigns that target the group of interest on multiple levels to create maximum behavior change.

\section{Reducing indoor tanning}

The dangers of UV exposure posed by tanning beds and devices have prompted health leaders and governments to intervene and limit the use of such products. In 2009, WHO reclassified UV tanning devices as a human carcinogen, ${ }^{90}$ citing a systematic review of seven studies demonstrating tanning bed exposure before age 35 was associated with relative risk of 1.75 (95\% CI 1.35-2.26) for melanoma. ${ }^{91}$

Within the past year, the FDA reclassified UV lamps from class I (general controls) to class II devices (special controls), thus increasing regulation and issued a "black box warning" requiring device labeling that people younger than age 18 should not use sunlamp products..$^{92}$ However, this reclassification carried no effective limitation at the point of service, which has been left to the discretion of individual states. In the USA, 23 of 50 states have enacted indoor tanning bans for minors, but laws among states are heterogeneous. Certain states prohibit indoor tanning for those 14 and younger, and other states extend the ban to teenagers 15 years, 16 years, or 17 years of age.$^{93}$ Enforcement of existing laws is sporadic, with underage tanners purchasing indoor tanning sessions from $81 \%$ of approached facilities in one study. ${ }^{94}$ Several member countries in the European Union also have bans for minors, ${ }^{95}$ and two countries have banned indoor tanning for all ages, Brazil in $2011^{95}$ and Australia in $2015 .{ }^{96}$
Multiple interventions may be needed to simultaneously target individual and societal beliefs about the attractiveness of a tanned appearance in conjunction with educating parents, launching school-based programs, and leveraging celebrity influence. Table 4 outlines the different target levels to be considered when created educational campaigns to combat indoor tanning. Continual assessment and evaluation of outcomes would inform progress of programs and help dictate future programming directions. ${ }^{97}$

\section{Summary}

Early diagnosis of melanoma provides opportunities for improved patient survival, better quality of life, and additional cost savings for health care systems. Primary prevention techniques include physician counseling and skin-protection behaviors that reduce UV exposure. Governments play a role by introducing policies that encourage and promote skin protection, such as sunscreen regulation and bans on tanning devices, especially for minors. Secondary prevention strategies can be used by PCPs or dermatologists and may be supported by technology such as dermoscopy and total-body photography.

There is a general lack of worldwide consensus on optimal screening of high-risk patients. Frequent skin self-exams, physical exams, dermoscopy, and a low intervention threshold are the mainstays of early detection, but recommended intervals for clinical encounters range between 3 months and 12 months and vary by organization, patient anxiety level, and self-awareness. Surveillance for recurrent disease varies by provider and country as well. Ultrasound appears most sensitive for detecting nodal metastases, and PET/CT 
is the most sensitive for distant metastatic disease. However, the survival benefit for detection of surgically resectable recurrences is minimal, and more research is needed to identify how early detection of recurrence can maximally benefit these patients.

\section{Acknowledgments}

The authors would like to thank the Department of Scientific Publications at MD Anderson for their editing assistance. This work was supported in part by National Institutes of Health grant T32 CA009599.

\section{Disclosure}

The authors declare no conflicts of interest in this work.

\section{References}

1. Siegel RL, Miller KD, Jemal A. Cancer statistics, 2015. CA Cancer J Clin. 2015;65(1):5-29.

2. Cooper S. The First Lines of the Theory and Practice of Surgery. London: Longman, Orme, and Co; 1840.

3. Howlader N, Noone A, Krapcho M, et al, editors. SEER Cancer Statistics Review, 1975-2011. Available from: http://seer.cancer.gov/ csr/1975_2011/. Accessed October 3, 2015.

4. Balch CM, Gershenwald JE, Soong SJ, et al. Final version of 2009 AJCC melanoma staging and classification. J Clin Oncol. 2009;27(36): 6199-6206.

5. Xing Y, Chang GJ, Hu CY, et al. Conditional survival estimates improve over time for patients with advanced melanoma: results from a population-based analysis. Cancer. 2010;116(9):2234-2241.

6. National Comprehensive Cancer Network. NCCN Clinical Practice Guidelines in Oncology (NCCN Guidelines): Melanoma. Version 2; 2015. Available from: http://www.nccn.org/professionals/physician_ gls/pdf/melanoma.pdf. Accessed February 23, 2015.

7. Morton DL, Cochran AJ, Thompson JF, et al; Multicenter Selective Lymphadenectomy Trial Group. Sentinel node biopsy for early-stage melanoma: accuracy and morbidity in MSLT-I, an international multicenter trial. Ann Surg. 2005;242(3):302-311. [discussion 311-303].

8. Hyngstrom JR, Chiang YJ, Cromwell KD, et al. Prospective assessment of lymphedema incidence and lymphedema-associated symptoms following lymph node surgery for melanoma. Melanoma Res. 2013;23(4):290-297.

9. Chang SB, Askew RL, Xing Y, et al. Prospective assessment of postoperative complications and associated costs following inguinal lymph node dissection (ILND) in melanoma patients. Ann Surg Oncol. 2010;17(10):2764-2772.

10. Robert C, Karaszewska B, Schachter J, et al. Improved overall survival in melanoma with combined dabrafenib and trametinib. N Engl J Med. 2015;372(1):30-39.

11. Hodi FS, Lee S, McDermott DF, et al. Ipilimumab plus sargramostim vs ipilimumab alone for treatment of metastatic melanoma: a randomized clinical trial. JAMA. 2014;312(17):1744-1753.

12. Flaherty LE, Othus M, Atkins MB, et al. Southwest Oncology Group S0008: a phase III trial of high-dose interferon Alfa- $2 \mathrm{~b}$ versus cisplatin, vinblastine, and dacarbazine, plus interleukin-2 and interferon in patients with high-risk melanoma - an intergroup study of cancer and leukemia Group B, Children's Oncology Group, Eastern Cooperative Oncology Group, and Southwest Oncology Group. J Clin Oncol. 2014;32(33):3771-3778.

13. Ziefle S, Egberts F, Heinze S, et al. Health-related quality of life before and during adjuvant interferon-alpha treatment for patients with malignant melanoma (DeCOG-trial). J Immunother. 2011;34(4):403-408.
14. Bottomley A, Coens C, Suciu S, et al. Adjuvant therapy with pegylated interferon alfa- $2 \mathrm{~b}$ versus observation in resected stage III melanoma: a phase III randomized controlled trial of health-related quality of life and symptoms by the European Organisation for Research and Treatment of Cancer Melanoma Group. J Clin Oncol. 2009;27(18):2916-2923.

15. Tromme I, Devleesschauwer B, Beutels P, et al. Health-related quality of life in patients with melanoma expressed as utilities and disability weights. Br J Dermatol. 2014;171(6):1443-1450.

16. Schlesinger-Raab A, Schubert-Fritschle G, Hein R, et al. Quality of life in localised malignant melanoma. Ann Oncol. 2010;21(12):2428-2435.

17. Bickers DR, Lim HW, Margolis D, et al; American Academy of Dermatology Association, Society for Investigative Dermatology. The burden of skin diseases: 2004 a joint project of the American Academy of Dermatology Association and the Society for Investigative Dermatology. J Am Acad Dermatol. 2006;55(3):490-500.

18. Morris S, Cox B, Bosanquet N. Cost of skin cancer in England. Eur J Health Econ. 2009;10(3):267-273.

19. The World Bank. Health Expenditure Per Capita (Current US\$); 2015. Available from: http://data.worldbank.org/indicator/SH.XPD. PCAP?page $=2$.

20. Alexandrescu DT. Melanoma costs: a dynamic model comparing estimated overall costs of various clinical stages. Dermatol Online J. 2009;15(11):1.

21. Reyes C, DaCosta Byfield S, Linke R, Satram-Hoang S, Teitelbaum AH. The burden of metastatic melanoma: treatment patterns, healthcare use (utilization), and costs. Melanoma Res. 2013;23(2):159-166.

22. Davis KL, Mitra D, Kotapati S, Ibrahim R, Wolchok JD. Direct economic burden of high-risk and metastatic melanoma in the elderly: evidence from the SEER-Medicare linked database. Appl Health Econ Health Policy. 2009;7(1):31-41.

23. Tsao H, Rogers GS, Sober AJ. An estimate of the annual direct cost of treating cutaneous melanoma. J Am Acad Dermatol. 1998;38(5 pt 1): 669-680.

24. Seidler AM, Pennie ML, Veledar E, Culler SD, Chen SC. Economic burden of melanoma in the elderly population: population-based analysis of the surveillance, epidemiology, and end results (SEER) - Medicare data. Arch Dermatol. 2010;146(3):249-256.

25. Yabroff KR, Lamont EB, Mariotto A, et al. Cost of care for elderly cancer patients in the United States. J Natl Cancer Inst. 2008;100(9):630-641.

26. Souza RJ, Mattedi AP, Rezende ML, Correa Mde P, Duarte EM. An estimate of the cost of treating melanoma disease in the state of Sao Paulo - Brazil. An Bras Dermatol. 2009;84(3):237-243.

27. Cormier JN, Xing Y, Ding M, et al. Cost effectiveness of adjuvant interferon in node-positive melanoma. J Clin Oncol. 2007;25(17): $2442-2448$.

28. Losina E, Walensky RP, Geller A, et al. Visual screening for malignant melanoma: a cost-effectiveness analysis. Arch Dermatol. 2007;143(1): $21-28$.

29. Gordon LG, Rowell D. Health system costs of skin cancer and costeffectiveness of skin cancer prevention and screening: a systematic review. Eur J Cancer Prev. 2015;24(2):141-149.

30. Johnson N, Mant D, Newton J, Yudkin PL. Role of primary care in the prevention of malignant melanoma. Br J Gen Pract. 1994;44(388): 523-526.

31. Petterson SM, Liaw WR, Tran C, Bazemore AW. Estimating the residency expansion required to avoid projected primary care physician shortages by 2035. Ann Fam Med. 2015;13(2):107-114.

32. Zouridakis G, Wadhawan T, Situ N, et al. Melanoma and other skin lesion detection using smart handheld devices. Methods Mol Biol. 2015;1256:459-496.

33. Stoecker WV, Rader RK, Halpern A. Diagnostic inaccuracy of smartphone applications for melanoma detection: representative lesion sets and the role for adjunctive technologies. JAMA Dermatol. 2013; 149(7):884.

34. Kassianos AP, Emery JD, Murchie P, Walter FM. Smartphone applications for melanoma detection by community, patient and generalist clinician users: a review. Br J Dermatol. 2015;172(6):1507-1518. 
35. Feig BW, Ching CD. The MD Anderson Surgical Oncology Handbook. 5th ed. Philadelphia, PA: Lippincott Williams \& Wilkins; 2012:66-67.

36. Linos E, Swetter SM, Cockburn MG, Colditz GA, Clarke CA. Increasing burden of melanoma in the United States. J Invest Dermatol. 2009;129(7):1666-1674.

37. Balch CM, Thompson JF, Gershenwald JE, et al. Age as a predictor of sentinel node metastasis among patients with localized melanoma: an inverse correlation of melanoma mortality and incidence of sentinel node metastasis among young and old patients. Ann Surg Oncol. 2014;21(4):1075-1081.

38. Siegel R, Ma J, Zou Z, Jemal A. Cancer statistics, 2014. CA Cancer J Clin. 2014;64(1):9-29.

39. Gandini S, Sera F, Cattaruzza MS, et al. Meta-analysis of risk factors for cutaneous melanoma: II. Sun exposure. Eur J Cancer. 2005;41(1): $45-60$.

40. Goodson AG, Grossman D. Strategies for early melanoma detection: Approaches to the patient with nevi. JAm Acad Dermatol. 2009;60(5): 719-735. [quiz 736-718].

41. Carli P, de Giorgi V, Chiarugi A, et al. Addition of dermoscopy to conventional naked-eye examination in melanoma screening: a randomized study. J Am Acad Dermatol. 2004;50(5):683-689.

42. Watts CG, Dieng M, Morton RL, Mann GJ, Menzies SW, Cust AE. Clinical practice guidelines for identification, screening and follow-up of individuals at high risk of primary cutaneous melanoma: a systematic review. Br J Dermatol. 2015;172(1):33-47.

43. Chatzinasiou F, Lill CM, Kypreou K, et al. Comprehensive field synopsis and systematic meta-analyses of genetic association studies in cutaneous melanoma. J Natl Cancer Inst. 2011;103(16):1227-1235.

44. Eckerle Mize D, Bishop M, Resse E, Sluzevich J. Familial atypical multiple mole melanoma syndrome. In: Riegert-Johnson DL, Boardman LA, Hefferon T, Roberts M, editors. Cancer Syndromes. Bethesda, MD: National Center for Biotechnology Information (US); 2009.

45. Haenssle HA, Korpas B, Hansen-Hagge C, et al. Selection of patients for long-term surveillance with digital dermoscopy by assessment of melanoma risk factors. Arch Dermatol. 2010;146(3):257-264.

46. Bichakjian CK, Halpern AC, Johnson TM, et al; American Academy of Dermatology. Guidelines of care for the management of primary cutaneous melanoma. American Academy of Dermatology. J Am Acad Dermatol. 2011;65(5):1032-1047.

47. health.govt.nz [webpage on the Internet]. Clinical practice guidelines for the management of melanoma in Australia and New Zealand; 2008 [cited June 02, 2008]. Available from: http://www.health.govt. nz/publication/clinical-practice-guidelines-management-melanomaaustralia-and-new-zealand. Accessed August 25, 2015.

48. BC Cancer Agency. Cancer management guidelines: melanoma. Vancouver: BC Cancer Agency. Available from: http://www.bccancer. bc.ca/health-professionals/professional-resources/cancer-managementguidelines/skin/melanoma. Accessed on May 1, 2015.

49. Finnish Medical Society Duodecim and Chirugia Plastici Fenniaen Working Group. Ihomelanooma (Melanoma of the Skin). Helsinki: Duodecim Medical Publications Ltd, 2012.

50. Pflugfelder A, Kochs C, Blum A, et al. Malignant melanoma S3-guideline "diagnosis, therapy and follow-up of melanoma". J Dtsch Dermatol Ges. 2013;11(Suppl 6):1-116.

51. Dutch Working Group on Melanoma. Melanoma guideline 2012. Utrecht: Integraal Kankercentrum Nederland; 2013. Available from: http://www.oncoline.nl/uploaded/docs/melanoom/201208_vertaling $\% 20$ Richtlijn\%20melanoom\%20def.pdf. Accessed August 25, 2015.

52. Guidelines Working Group. National guidelines for diagnosis, treatment and follow-up of malignant melanomas. Oslo: Norwegian Directorate of Health. 2011.

53. Watts CG, Cust AE, Menzies SW, Coates E, Mann GJ, Morton RL. Specialized surveillance for individuals at high risk for melanoma: a cost analysis of a high-risk clinic. JAMA Dermatol. 2015;151(2):178-186.

54. Kasparian NA, McLoone JK, Meiser B. Skin cancer-related prevention and screening behaviors: a review of the literature. J Behav Med. 2009;32(5):406-428.
55. Bertolin M, Cercatto MC, Requena C, et al. Awareness, attitude, and adherence to preventive measures in patients at high risk of melanoma. A cross-sectional study on 185 patients. J Cancer Educ. Epub 2014 Dec 16.

56. Berwick M, Begg CB, Fine JA, Roush GC, Barnhill RL. Screening for cutaneous melanoma by skin self-examination. $J$ Nat Cancer Inst. 1996;88(1):17-23.

57. Berg AO, Allan JD. Introducing the third US Preventive Services Task Force. Am J Prev Med. 2001;20(3 Suppl):3-4.

58. Azoury SC, Lange JR. Epidemiology, risk factors, prevention, and early detection of melanoma. Surg Clin North Am. 2014;94(5):957.

59. Cromwell KD, Ross MI, Xing Y, et al. Variability in melanoma posttreatment surveillance practices by country and physician specialty: a systematic review. Melanoma Res. 2012;22(5):376-385.

60. Xing Y, Cromwell KD, Cormier JN. Review of diagnostic imaging modalities for the surveillance of melanoma patients. Dermatol Res Pract. 2012;2012:941921

61. Mathews JD, Forsythe AV, Brady Z, et al. Cancer risk in 680,000 people exposed to computed tomography scans in childhood or adolescence: data linkage study of 11 million Australians. BMJ. 2013;346: f2360.

62. Xing Y, Bronstein Y, Ross MI, et al. Contemporary diagnostic imaging modalities for the staging and surveillance of melanoma patients: a meta-analysis. J Natl Cancer Inst. 2011;103(2):129-142.

63. Rueth NM, Xing Y, Chiang YJ, et al. Is surveillance imaging effective for detecting surgically treatable recurrences in patients with melanoma? A comparative analysis of stage-specific surveillance strategies. Ann Surg. 2014;259(6):1215-1222.

64. Leiter U, Buettner PG, Eigentler TK, Forschner A, Meier F, Garbe C. Is detection of melanoma metastasis during surveillance in an early phase of development associated with a survival benefit? Melanoma Res. 2010;20(3):240-246.

65. Michielin O, Hoeller C. Gaining momentum: New options and opportunities for the treatment of advanced melanoma. Cancer Treat Rev. Epub 2015 Jun 4

66. Armstrong BK, Kricker A. How much melanoma is caused by sun exposure? Melanoma Res. 1993;3(6):395-401.

67. Rigel DS. Cancer of the Skin. Philadelphia: Saunders; 2005.

68. Therapeutic Goods Administration. Australian Regulatory Guidelines for Sunscreens. Australia: Therapeutic Goods Administration; 2012.

69. Health Canada. Sunscreen Monograph; 2013. Available from: http:// webprod.hc-sc.gc.ca/nhpid-bdipsn/atReq.do?atid=sunscreen-ecranso laire\&. Accessed March 30, 2015.

70. US Food and Drug Administration. FDA Sheds Light on Sunscreen; 2012. Available from: http://www.fda.gov/forconsumers/consumerup dates/ucm258416.htm. Accessed March 30, 2015.

71. Cosmetics Europe. The European Commission Recommendation on the Efficacy of Sunscreen Products; n.d. Available from: https://www. cosmeticseurope.eu/using-cosmetics-colipa-the-european-cosmeticcosmetics-association/sun-products/the-european-commissionrecommendation-on-the-efficacy-of-sunscreen-products.html. Accessed March 30, 2015.

62. National Cancer Institute. National Cancer Institute: PDQ Skin Cancer Prevention. Available from: http://cancer.gov/cancertopics/pdq/preven tion/skin/HealthProfessional. Accessed March 30, 2015.

73. Gimotty PA, Glanz K. Sunscreen and melanoma: what is the evidence? J Clin Oncol. 2011;29(3):249-250.

74. Green AC, Williams GM, Logan V, Strutton GM. Reduced melanoma after regular sunscreen use: randomized trial follow-up. J Clin Oncol. 2011;29(3):257-263.

75. American Academy of Dermatology. Sunscreen FAQs; 2015. Available from: https://www.aad.org/media-resources/stats-and-facts/preventionand-care/sunscreen-faqs. Accessed April 10, 2015.

76. American Cancer Society. Can Melanoma Skin Cancer be Prevented? 2015. Available from: http://www.cancer.org/cancer/skincancer-melanoma/detailedguide/melanoma-skin-cancer-prevention. Accessed April $1,2015$. 
77. Cancer Council Australia. Preventing Skin Cancer; 2015; n.d. Available from: http://www.cancer.org.au/preventing-cancer/sun-protection/ preventing-skin-cancer/. Accessed March 31, 2015.

78. World Health Organization. Sun Protection. Available from: http://www. who.int/uv/sun_protection/en/. Accessed April 1, 2015.

79. Dennis LK, Vanbeek MJ, Beane Freeman LE, Smith BJ, Dawson DV, Coughlin JA. Sunburns and risk of cutaneous melanoma: does age matter? A comprehensive meta-analysis. Ann Epidemiol. 2008;18(8):614-627.

80. World Health Organization. Sun Protection and Schools: How to Make a Difference; 2003. Available from: http://www.who.int/uv/publications/ en/sunprotschools.pdf?ua=1. Accessed March 30, 2015.

81. US Environmental Protection Agency. Learn about SunWise; 2014. Available from: http://www2.epa.gov/sunwise/learn-about-sunwise. Accessed April 1, 2015.

82. Kyle JW, Hammitt JK, Lim HW, et al. Economic evaluation of the US Environmental Protection Agency's SunWise program: sun protection education for young children. Pediatrics. 2008;121(5):e1074-e1084.

83. Horsham C, Auster J, Sendall MC, et al. Interventions to decrease skin cancer risk in outdoor workers: update to a 2007 systematic review. BMC Res Notes. 2014;7:10.

84. Mayer JA, Slymen DJ, Clapp EJ, et al. Promoting sun safety among US Postal Service letter carriers: impact of a 2-year intervention. Am J Pub Health. 2007;97(3):559-565.

85. Davy L, Boyett T, Weathers L, Campbell RJ, Roetzheim RG. Sun protection counseling by pediatricians. Ambul Pediatr. 2002;2(3):207-211.

86. Dolan NC, Ng JS, Martin GJ, Robinson JK, Rademaker AW. Effectiveness of a skin cancer control educational intervention for internal medicine housestaff and attending physicians. J Gen Intern Med. 1997;12(9):531-536.

87. Bandi P, Cokkinides VE, Weinstock MA, Ward EM. Physician sun protection counseling: prevalence, correlates, and association with sun protection practices among US adolescents and their parents, 2004. Prev Med. 2010;51(2):172-177.

88. Robinson JD, Silk KJ, Parrott RL, Steiner C, Morris SM, Honeycutt C. Healthcare providers' sun-protection promotion and at-risk clients' skin-cancer-prevention outcomes. Prev Med. 2004;38(3):251-257.

89. US Preventive Services Task Force. Recommendation Summary; 2012 Available from: http://www.uspreventiveservicestaskforce.org/Page/ Topic/recommendation-summary/skin-cancer-counseling. Accessed March 30, 2015.

90. El Ghissassi F, Baan R, Straif K, et al. A review of human carcinogens part D: radiation. Lancet Oncol. 2009;10(8):751-752.

91. International Agency for Research on Cancer Working Group on Artificial Ultraviolet Light and Skin Cancer. The association of use of sunbeds with cutaneous malignant melanoma and other skin cancers: A systematic review. Int J Cancer. 2007;120(5):1116-1122.

92. Food, Drug Administration HHS. General and plastic surgery devices: reclassification of ultraviolet lamps for tanning, henceforth to be known as sunlamp products and ultraviolet lamps intended for use in sunlamp products. Final order. Fed Regist. 2014;79(105):31205-31214.

93. National Conference of State Legislatures. Indoor Tanning Restrictions for Minors - A State-by-State Comparison. Available from: http://www ncsl.org/research/health/indoor-tanning-restrictions.aspx. Accessed March 11, 2015.

94. Forster JL, Lazovich D, Hickle A, Sorensen G, Demierre MF. Compliance with restrictions on sale of indoor tanning sessions to youth in Minnesota and Massachusetts. J Am Acad Dermatol. 2006;55(6):962-967.

95. Pawlak MT, Bui M, Amir M, Burkhardt DL, Chen AK, Dellavalle RP. Legislation restricting access to indoor tanning throughout the world. Arch Dermatol. 2012;148(9):1006-1012.

96. Mulcahy N. Australia Bans Tanning Salons; 2015. Available from: http:// www.medscape.com/viewarticle/838407. Accessed March 11, 2015.

97. Holman DM, Fox KA, Glenn JD, et al. Strategies to reduce indoor tanning: current research gaps and future opportunities for prevention. Am J Prev Med. 2013;44(6):672-681.
98. Australian-Cancer-Network-Melanoma-Guidelines-RevisionWorking-Party. Clinical Practice Guidelines for the Management of Melanoma in Australia and New Zealand. Wellington: Sydney and New Zealand Guidelines Group; 2008.

99. Thompson JF, Shaw HM, Stretch JR, McCarthy WH, Milton GW. The Sydney Melanoma Unit - a multidisciplinary melanoma treatment center. Surg Clin North Am. 2003;83(2):431-451.

100. Francken AB, Accortt NA, Shaw HM, et al. Follow-up schedules after treatment for malignant melanoma. Br J Surg. 2008;95(11):1401-1407.

101. Kersey PA, Iscoe NA, Gapski JA, et al. The value of staging and serial follow-up investigations in patients with completely resected, primary, cutaneous malignant melanoma. Br J Surg. 1985;72(8):614-617.

102. Garbe C, Hauschild A, Volkenandt M, et al. Evidence and interdisciplinary consense-based German guidelines: diagnosis and surveillance of melanoma. Melanoma Res. 2007;17(6):393-399.

103. Ugurel S, Enk A. Skin cancer: follow-up, rehabilitation, palliative and supportive care. J Dtsch Dermatol Ges. 2008;6(6):492-498. [quiz 499].

104. Garbe C, Paul A, Kohler-Späth H, et al. Prospective evaluation of a follow-up schedule in cutaneous melanoma patients: recommendations for an effective follow-up strategy. J Clin Oncol. 2003;21(3): $520-529$

105. Roberts DL, Anstey AV, Barlow RJ, et al; British Association of Dermatologists, Melanoma Study Group. UK guidelines for the management of cutaneous melanoma. Br J Dermatol. 2002;146(1):7-17.

106. Meier F, Will S, Ellwanger U, et al. Metastatic pathways and time courses in the orderly progression of cutaneous melanoma. $\mathrm{Br} J$ Dermatol. 2002;147(1):62-70.

107. Marsden JR, Newton-Bishop JA, Burrows L, et al; British Association of Dermatologists (BAD) Clinical Standards Unit. Revised UK guidelines for the management of cutaneous melanoma 2010. J Plast Reconstr Aesthet Surg. 2010;63(9):1401-1419.

108. NCCN Clinical Practice Guidelines in Oncology: Melanoma; 2010. Available from: http:/www.nccn.org/professionals/physician_gls/ PDF/melanoma.pdf. Accessed August 22, 2011.

109. Sober AJ, Chuang TY, Duvic M, et al. Guidelines of care for primary cutaneous melanoma. J Am Acad Dermatol. 2001;45(4):579-586.

110. American Cancer Society, National Comprehensive Cancer Network. Melanoma: treatment guidelines for patients (part 2). Dermatol Nurs. 2005;17(3):191-198.

111. Olson JA Jr, Jaques DP, Coit DG, Hwu WJ. Staging work-up and post-treatment surveillance of patients with melanoma. Clin Plast Surg. 2000;27(3):377-390, viii.

112. Romero JB, Stefanato CM, Kopf AW, Bart RS. Follow-up recommendations for patients with stage I malignant melanoma. J Dermatol Surg Oncol. 1994;20(3):175-178.

113. Rumke P, van Everdingen JE. Consensus on the management of melanoma of the skin in The Netherlands. Dutch Melanoma Working Party. Eur J Cancer. 1992;28(2-3):600-604.

114. Nieweg OE, Kroon BB. The conundrum of follow-up: should it be abandoned? Surg Oncol Clin N Am. 2006;15(2):319-330.

115. Kroon BB, Nieweg OE, Hoekstra HJ, Lejeune FJ. Principles and guidelines for surgeons: management of cutaneous malignant melanoma. European Society of Surgical Oncology Brussels. Eur J Surg Oncol. 1997;23(6):550-558.

116. Francken AB, Bastiaannet E, Hoekstra HJ. Follow-up in patients with localised primary cutaneous melanoma. Lancet Oncol. 2005;6(8): 608-621.

117. Dummer R, Panizzon R, Bloch PH, Burg G. Updated Swiss guidelines for the treatment and follow-up of cutaneous melanoma. Dermatology. 2005;210(1):39-44.

118. Dummer R, Guggenheim M, Arnold AW, Braun R, von Moos R. Updated Swiss guidelines for the treatment and follow-up of cutaneous melanoma. Swiss Med Wkly. 2011;141:w13320.

119. Mancebo SE, Hu JY, Wang SQ. Sunscreens: a review of health benefits, regulations, and controversies. Dermatol Clin. 2014;32(3): 427-438, x. 


\section{Publish your work in this journal}

Patient Related Outcome Measures is an international, peer-reviewed, open access journal focusing on treatment outcomes specifically relevant to patients. All aspects of patient care are addressed within the journal and practitioners from all disciplines are invited to submit their work as well as healthcare researchers and patient support groups.

The manuscript management system is completely online and includes a very quick and fair peer-review system. Visit http://www.dovepress. com/testimonials.php to read real quotes from published authors.

Submit your manuscript here: http://www.dovepress.com/patient-related-outcome-measures-journa| 